\title{
Time-dependent, non-monotonic response of warm convective cloud fields to changes in aerosol loading
}

\section{Guy Dagan et al.}

Correspondence to: Ilan Koren (ilan.koren@weizmann.ac.il)

The copyright of individual parts of the supplement might differ from the CC BY 3.0 License. 


\section{S.1 Mean size and number of drops}

Figure S1 presents vertical profiles of the mean concentration and mean drop size per height. It demonstrates that at the cloudy layer $(\mathrm{H}>500 \mathrm{~m})$ the mean drop size decreases with aerosol loading, while its concentration increases (Twomey, 1977). Below cloud base the trend is reversed - larger rain drops and lower concentration under more polluted conditions (similar to what was shown in Altaratz et al., 2008).
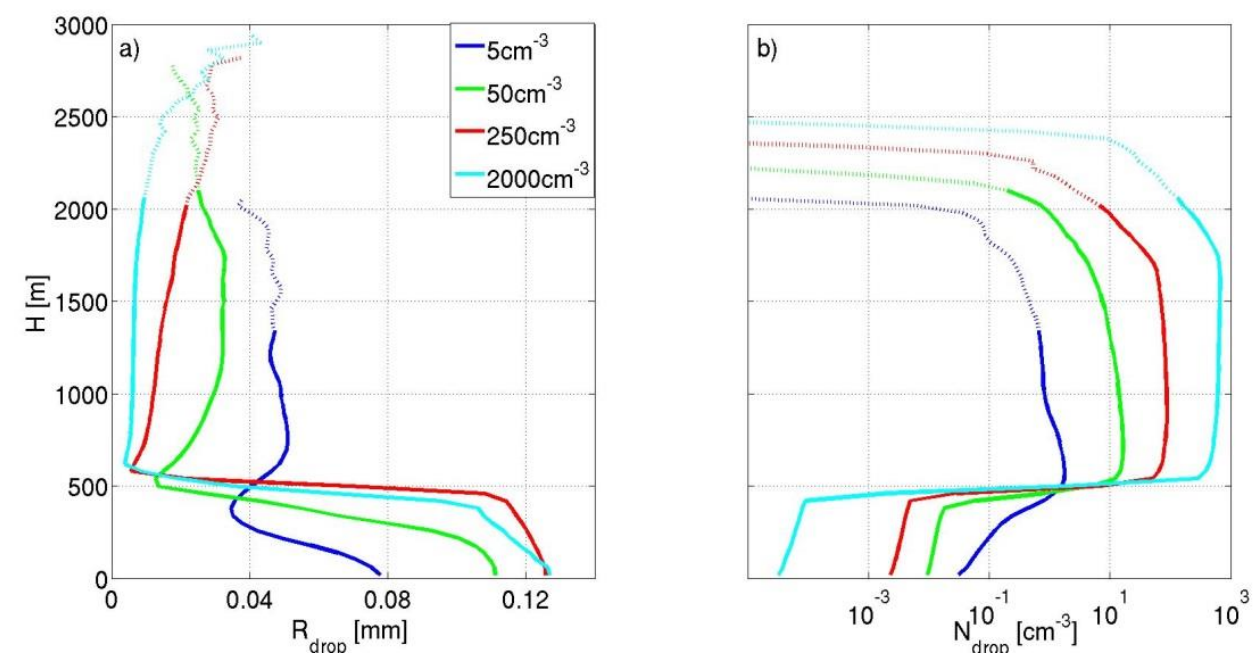

Figure S1. Vertical profiles of a) the mean (over time and domain) drop radius, and b) the mean (over the second two hours of simulation - after the spin-up time) of drop maximum concentration. These results include both cloud and raindrops for four simulations (with aerosol loading levels of $5 \mathrm{~cm}^{-3}-$ blue, $50 \mathrm{~cm}^{-3}-$ green, $250 \mathrm{~cm}^{-3}-$ red, and $2000 \mathrm{~cm}^{-3}$ - cyan). Doted parts of the curves represent heights in which the total liquid water mass was less than $1 \%$ of the maximum total mass (Fig. 4b) to avoid conclusions based on small statistics.

\section{S.2 Mean condensation and evaporation rates}

Figure S2 presents vertical profiles of the mean (over time) of the condensation and evaporation rates, per height, for four simulations with different aerosol loading. It 
demonstrates the increase in both condensation and evaporation rates with aerosol loading.

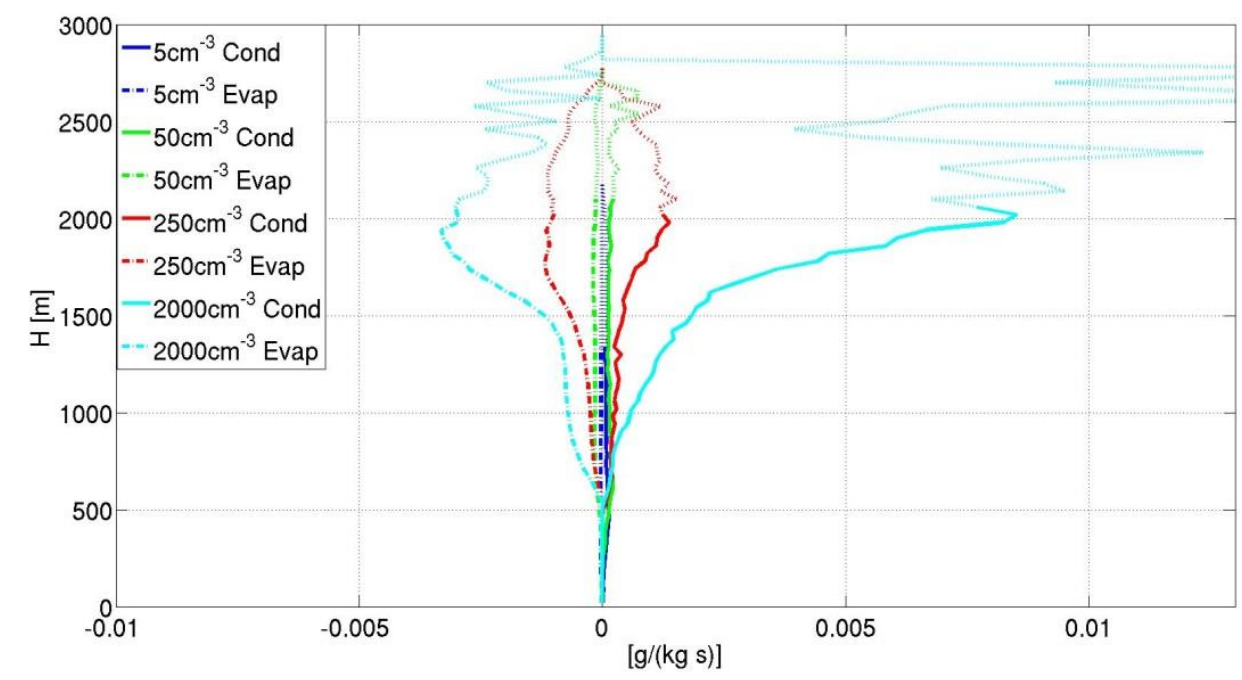

Figure S2. Domain's mean condensation (solid lines) and evaporation (dashed lines) tendencies for four different simulations conducted with different aerosol concentration levels $\left(5 \mathrm{~cm}^{-3}\right.$ blue, $50 \mathrm{~cm}^{-3}$ green, $250 \mathrm{~cm}^{-3}$ red and $2000 \mathrm{~cm}^{-3}$ cyan). Note that doted parts of the curves represent heights in which the total liquid water mass was less than $1 \%$ of the maximum total mass (Fig. 4b).

\section{S.3 Evolution of thermodynamic conditions}

Figure S3 presents the temporal change in vertical profiles of the temperature (left column) and water vapor mixing ratio (right column) for clean $\left(50 \mathrm{~cm}^{-3}-\right.$ upper row) and polluted (2000 $\mathrm{cm}^{-3}$ - lower row) conditions. It demonstrates that under clean conditions the cloudy layer $(\mathrm{H} \sim 500-1500 \mathrm{~m})$ becomes warmer and dryer with time while the sub-cloud layer becomes colder and wetter. On the other hand, under polluted conditions the trend is different and the most significant change occurs at the inversion layer which significantly cools and becomes wetter with time 

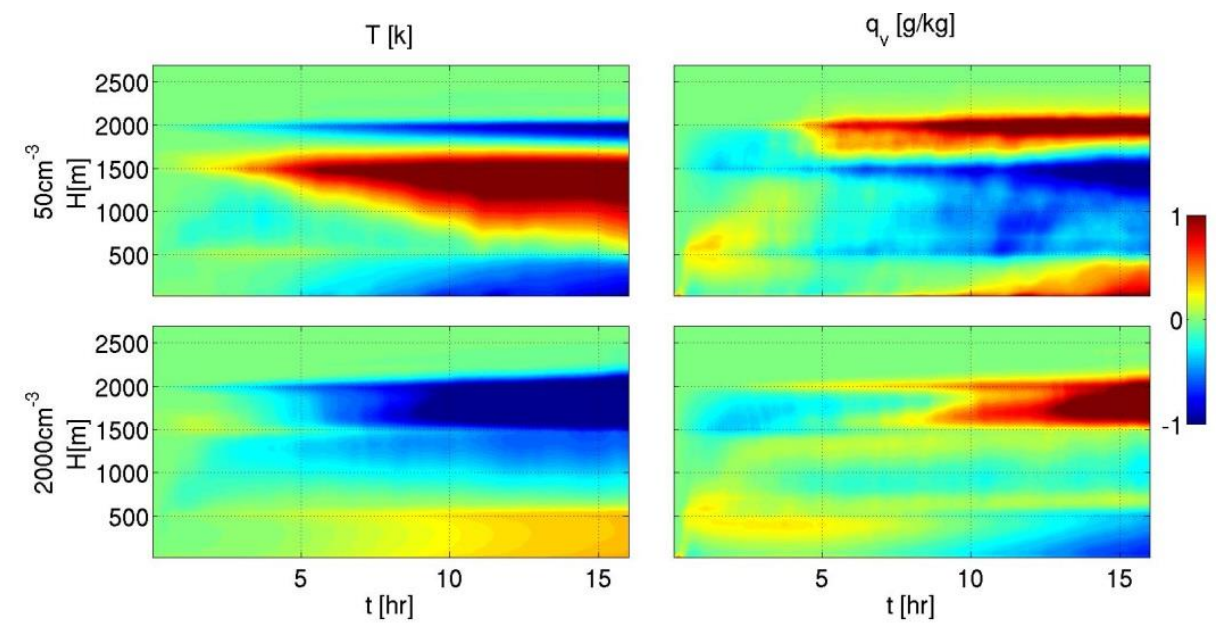

Fig. S3 Temporal changes compared to the initial profiles of mean environmental temperature $[\mathrm{K}]$ (left) and mean water vapor mixing ratio $[\mathrm{g} / \mathrm{kg}]$ (right). For two different simulations with aerosol concentrations of $50 \mathrm{~cm}^{-3}$ (clean - upper row) and $2000 \mathrm{~cm}^{-3}$ (polluted - lower row).

\section{$\underline{\text { References }}$}

Altaratz, O., I. Koren, T. Reisin, A. Kostinski, G. Feingold, Z. Levin, and Y. Yin: Aerosols' influence on the interplay between condensation, evaporation and rain in warm cumulus cloud, Atmospheric Chemistry and Physics, 8(1), 15-24, 2008.

Twomey, S.: The influence of pollution on the shortwave albedo of clouds, Journal of the atmospheric sciences, 34(7), 1149-1152, 1977. 